\title{
Philippine bird taxonomy and conservation, a response to Collar
}

\author{
A. TOWNSEND PETERSON
}

\section{Summary}

Collar (2007) attacked a recent paper of mine (Peterson 2006) on a number of grounds; he raised some valid points, and detected some errors in detail. Here, I respond to his criticisms, clarify misunderstandings, and urge the field to move beyond the status quo to consider the need for new taxonomic viewpoints to benefit bird conservation globally.

\section{Introduction}

A recent paper of mine (Peterson 2006) was the subject of a letter from Collar (2007), who raised several points to which I feel obliged to respond. My original paper simply offered a list of currently recognized Philippine bird species that appear to consist of multiple, distinct, diagnosable subunits, and that probably warrant detailed study. The paper, couched amply in caveats that it was just a first step and that no formal taxonomic or nomenclatural changes were to be proposed, set out to emphasize only that ample taxonomic work remains to be done in the region, and that such taxonomic work does "matter" in terms of biodiversity conservation. Collar's remarks, however, reveal a surprising misinterpretation of my intent in this paper, and indeed of several basic tenets of taxonomy and systematics. Here, I avoid the temptation to respond to Collar point by point, and rather focus on the important issues.

\section{Collar's criticisms}

My paper was stated at the outset to be a "first-pass" review of currently recognized Philippine bird species (sensu Dickinson et al. 1991) to signal species that show discrete among-population variation. The idea was to stimulate more detailed studies that would probably reveal these forms to consist of multiple species. Because of the preliminary nature of the review, I proposed no formal taxonomic changes; rather, the idea was to list taxa of potential interest for future work.

Collar criticized my use of the 1991 Birds of the Philippines summary (Dickinson et al. 1991) as a base list from which to observe changes. I chose this work as a starting point because it was the last comprehensive summary of the birds of the country when I began the study, well before the publication of the field guide for the country (Kennedy et al. 2000). I believed it best to work from a single comprehensive authority, rather than from an amalgam of current opinion that is not always stable regarding a particular taxon. My omission of citations for work done since that volume was in no way intended to detract from the insights of previous workers, but rather reflected the "first-pass" nature of the paper.

Collar also levelled criticisms on several other grounds, such as my not including consideration of vocal and molecular characters. I wholeheartedly agree with this criticism, and for this reason have prioritized additional fieldwork in the region: until series of modern, information-rich specimens are assembled that include tissue samples for molecular analysis and 
associated sound recordings, however, such deeper insights are difficult. Collar's point that I "unaccountably omitted" four major museums with important Philippine holdings is simply a reflection of the fact that I had no opportunity to visit those institutions while developing the analyses presented. Thorough systematic revisions take a lot of work, and the dispersed nature of good series and key specimens across multiple institutions makes for special challenges in assembling a comprehensive view of a situation; hence, the explicitly stated preliminary nature of my review.

Collar's comments about the adequacy of the scientific specimen record of Philippine birds are perhaps valid in the specific (i.e. how many specimens exist for Dicrurus hottentotus menagei, error mine), but are not for the broader picture. To assemble a broad and consistent new view of Philippine bird diversity, information regarding very diverse character sets will be necessary: morphology, coloration, vocalizations and molecular variation. The current specimen record, while large for the Philippines in comparison with, for example, Sulawesi, simply does not offer the detailed series of modern, information-rich material that will be required for definitive study; combining existing material with strategically collected, information-rich new material will make more comprehensive studies possible.

Collar complained that the paper "lays claim to a number of revisions which are in fact already published elsewhere", as if I were taking credit for new taxonomic insights. Unfortunately, he misinterpreted my verbiage: I termed these taxa "heretofore unrecognized distinct populations within currently recognized species", but with the word "unrecognized" in a strict taxonomic sense. I was not in any way seeking to lay claim to new insights, but rather was simply stating that these potential species had not formally been recognized taxonomically in the authority chosen (Dickinson et al. 1991).

\section{Species concepts}

At the outset of his commentary, Collar referred to "the use of species concepts (rather than taxonomy per se)", as if some means exists for separating taxonomy from the concepts on which the classification is based; this comment sets the tone for the remainder of the piece. He reserved an entire section for criticizing my reliance on the phylogenetic species concept (PSC), and all of the problems that he sees with that concept, as he has done in other such criticisms (Collar and Spottiswoode 2005). Unfortunately, however, my Methods section stated: "this operational approach can be taken as a first pass towards a taxonomic treatment under the evolutionary species concept, and certainly would qualify as a phylogenetic species concept treatment as well" (italics mine). From this sentence, it is clear that I am not a PSC zealot. Rather, I follow the evolutionary species concept (ESC) ideas of independent evolutionary trajectories (Wiley 1978, Wiley and Mayden 2000) as a criterion for recognition as full species, and not the PSC.

The species concept point is more serious than Collar appears to realize. He focuses considerable attention on what are field marks versus what is identifiable, and on the issue of character triviality under the PSC. The ESC avoids these problems by focusing on the establishment of independence of evolutionary trajectories (as opposed to the establishment of reproductive isolation), and by separating conceptual basis from operational definition. What is more, the ESC avoids many problems inherent in the biological species concept (BSC) (Peterson and Navarro-Sigüenza 2006), the most relevant in the Philippines being that of treatment of differentiated allopatric populations. Hence, the issue is not one of "species concepts" versus taxonomy, but one of choosing a species concept that can capture important features of biodiversity in a quantitative, repeatable and defendable taxonomic framework.

\section{Conclusions}

Collar (2007) criticized my first-pass reassessment of Philippine species (Peterson 2006) on a number of grounds, but most of his criticisms are founded on what appears to be 
misunderstanding of systematic terminology and methods. He points out several omissions and inconsistencies in my lists, for which I am grateful, and his points serve to enrich the first-pass review of complexes of Philippine birds in need of systematic attention. My paper was explicitly and expressly intended as a preliminary assessment that can stimulate future work, and as such I offer few apologies.

Collar rightly corrects, amends and adds to my lists and descriptions, as I had hoped that he and/or others would do, but his comments are made in a conceptual vacuum ignoring major advances in modern systematics. My perception, considering this present attack in light of his previous such criticisms (e.g. Collar 1996, 1997, Collar and Spottiswoode 2005), is that Collar considers it necessary to defend the taxonomy that the conservation establishment creates and approves of against any change from outside, particularly if it would require conceptual rethinking and reconsideration.

Recent studies, however, have provided clear demonstrations of the key role of consistent application of species concepts in determining patterns of species richness, endemism and consequent conservation priority (Danielson and Treadaway 2004; Peterson and NavarroSigüenza 1999, Navarro-Sigüenza 2000). Depending on the concept followed, conservation priorities may shift from small peripheral isolated habitat patches to broad central areas, and some areas may be omitted from priority lists altogether. Hence, Collar's staunch defence of the status quo may result in loss of real elements of biodiversity.

Perhaps the best statement of my position on these issues can be drawn from a different opinion piece by Collar himself (Collar 1997). He stated:

Ideally, therefore, considerable technical detail is desirable .... On the other hand, time and resources may not easily permit such work, so that the rapid articulation of an opinion ... or its containment in a footnote ... or even indeed an assertion as flimsy and unrefereed as that for Sumatran Cochoa Cohoa beccarii (Collar and Andrew 1987), may have to suffice.

My effort was along these lines - a starting point and a first alternative-species-concept list of Philippine birds, in the hope of adding useful ideas to the literature. Do we, for example, believe that the several species of Penelopides hornbills that BirdLife International (200o) recognizes (and considers three as Endangered or Critical) are necessarily more important for conservation than the roughly similar number of disjunct differentiated forms of Turdus poliocephalus? Some of the latter are distributed over the same regions, and some are extremely limited in their geographic ranges. I hope that these publications can at least serve to stimulate new, detailed and forward-thinking taxonomic studies that can improve the current understanding and the possibilities for conservation of Philippine biodiversity.

\section{References}

Amadon, D. (1949) The seventy-five per cent rule for subspecies. Condor 51: 250-258.

BirdLife International (2000) Threatened birds of the world. Barcelona: Lynx Edicions.

Collar, N. J. (1996) Species concepts and conservation: a response to Hazevoet. Bird Conserv. Int. 6: 197-200.

Collar, N. J. (1997) Taxonomy and conservation: chicken and egg. Bull. Brit. Orn. Club 117: 122-136.
Collar, N. J. (2007) Philippine bird taxonomy and conservation: a commentary on Peterson (2006). Bird Conserv. Int.: 17: 103-113.

Collar, N. J. and Spottiswoode, C. N. (2005) Species limits in birds: a response to Watson. BioScience 55: 388-389.

Danielson, F. and Treadaway, C. G. (2004) Priority conservation areas for butterflies (Lepidoptera: Rhopalocera) in the Philippine islands. Anim. Conserv. 7: 79-92. 
Dickinson, E. C., Kennedy, R. S. and Parkes, K. C. (1991) The birds of the Philippines. Tring, U.K.: British Ornithologists' Union. Kennedy, R. S., Gonzales, P. C., Dickinson, E. C. and Miranda, H. C. J. (200o) A guide to the birds of the Philippines. Oxford: Oxford University Press.

Peterson, A. T. (2006) Taxonomy is important in conservation: a preliminary reassessment of Philippine species-level bird taxonomy. Bird Conserv. Int. 16: 155-173.

Peterson, A. T. and Navarro- Sigüenza, A. G. (1999) Alternate species concepts as bases for determining priority conservation areas. Conserv. Biol. 13: 427-431.
Peterson, A. T. and Navarro-Sigüenza, A. G. (2000) Western Mexico: a significant centre of avian endemism and challenge for conservation action. Cotinga 14: 42-46.

Peterson, A. T. and Navarro-Sigüenza, A. G. (2006) Consistency of taxonomic treatments: a response to Remsen (2005). Auk 123: 885-887.

Wiley, E. O. (1978) The evolutionary species concept reconsidered. Syst. Zool. 27: 17-26.

Wiley, E. O. and Mayden, R. L. (2000) The evolutionary species concept. Pp. 70-89 in Q. D. Wheeler and R. Meier, eds. Species concepts and phylogenetic theory: a debate, 200o. New York: Columbia University Press.

\section{A. TOWNSEND PETERSON}

Natural History Museum and Biodiversity Research Center, The University of Kansas, Lawrence, KA 66045, U.S.A. E-mail: town@ku.edu.

Received 2 January 2007; revision accepted 14 February 2007 